\title{
Knowledge Regarding Integrated Management of Neonatal and Childhood Illnesses (IMNCI) Among ANMS
}

\author{
Radhika. $\mathbf{M}^{1}$, Dr.( Mrs). Kasthuri .G \\ Ph .D Scholar, Professor CUM Vice principal, HOD, Dept of Child Health Nursing, Narayana College of Nursing, \\ Chinthareddypalem, Nellore \\ ${ }^{2}$ Professor, Consultant, Nursing Education, RGUHS, Bangalore, Karnataka, India
}

\begin{abstract}
Background of the Study: Around the world more than 10 million children under the age of five die every year and the world's poorest countries continue to bear the burden of these deaths. Levels of under-5 mortality vary widely across countries from 4 to over 280 deaths per 1000 live births. Child health has been high on the international agenda for over two decades now. The coverage of child-health interventions remains highly inadequate in India. The third National Family Health Survey (NFHS III) data showed that, in 2005-2006, only $43.5 \%$ of children were fully immunized; $26.2 \%$ of children, aged less than three years (under-3 children), suffering from diarrhoea, received oral rehydration salt (ORS) solution; and 64.2\% of children with acute respiratory infection (ARI) or fever in the last two weeks were taken to a health facility. Only $23 \%$ of under-three children received breastfeeding within one hour of birth, and 46.3\% aged 0-5 months were exclusively breastfed. ${ }^{2}$ Assessment is critical to know the degree of implementation of any program which aims to protect, promote and support the health of the weaker section of the society i.e. mothers and new born. In our country IMNCI is one such program which has been shown to be effective for Mothers and New born, and has been designed with the rural setting in mind. The multipurpose health workers at the SC have to take care of all the basic health needs of the rural population and thus become back-bone of the public health delivery system. Hence, it is very important to assess the level of their knowledge and practice in relation to key services delivered under IMNCI. Materials and Methods: Research design: This is a descriptive cross sectional study. The study subjects were health workers - female working in rural sub centers. Setting: the study was conducted in Rural PHCs \& SCs of the Nellore District, Andhra Pradesh. Sample size:224 ANMs working in all the 37 PHCs and the SCs under these PHCs in the Nellore District were included for the study. Sampling technique: stratified random sampling technique was adopted to select the subjects. Tools and techniques: Data were obtained by using self administered structured Questionnaire to assess the knowledge regarding classification and management of illness in neonates and children. Results: Among 224 ANMs only 27 (12\%) had moderately adequate Knowledge and $177(79.01 \%)$ had poor knowledge and 20(8.2\%) had adequate knowledge. Conclusion: Majority of the ANMs (F)have lack of knowledge in classification and management of neonate and children. This study concludes that ANMs need more supervision and training for better results.
\end{abstract}

Keywords: children, knowledge, illness management, ANMS, childhood illness.

\section{Introduction}

Children are important asset of any nation. Their nurture and solicitude are our responsibility. Programmes for children should find a prominent part in our national plans for the development of the country and especially the human resources, so that our children grow up to become robust citizens, physically fit, mentally alert and morally healthy, endowed with the skills and motivations needed by the society. ${ }^{1}$ As per 2001 census, India has the largest population of children in the world with approximately $42 \%$ of population below the age of 15 years including $15.42 \%$ (157.8 million children) between the age group of 0-6 years. Under-five mortality rate is $87 / 1000$ live births and it is nearly fifteen times higher than those of developed countries. ${ }^{2}$ Millions of children under five years of age die each year from diseases easily preventable like underweight, ${ }^{2-5}$ diarrhoea, pneumonia, measles, malaria ${ }^{4,5}$ and HIV/AIDS. ${ }^{4}$

Around the world more than 10 million children under the age of five die every year and the world's poorest countries continue to bear the burden of these deaths. Levels of under5 mortality vary widely across countries from 4 to over 280 deaths per 1000 live births. Child health has been high on the international agenda for over two decades now. The world summit for children in 1990 called for a worldwide reduction in child mortality below 70 deaths/1000 live births by the year 2000. Unfortunately this goal was not met. The Millennium Development goal on under-five mortality is to reduce the rate by two-thirds between 1990 and 2015. For developing regions this would mean a reduction from 105 to 35 deaths per 1000 live births, and for South Asia a reduction from 126 to 42. For India, attaining the millennium development goal would imply a reduction of the under-five mortality rate to 41 per 1000 live births by 2015 .

It is estimated that 2.1 million children in India die before reaching 5 years of age.

These children account for approximately one-fifth of the worldwide deaths occurring in this age group. Infant mortality in India has declined over the past four decades, from 146 per 1000 live births to 72 per 1000 live births, however this decline has slowed during the past 8-10 years [1]. Most of the reduction in mortality over the last decade has been in children between the age of 1 month and 5 years. Currently almost $2 / 3$ rd of infant mortality is comprised of neonates, most of who die within the first week of life [1]. In an effort to address high neonatal death rates, along with 


\section{International Journal of Science and Research (IJSR) \\ ISSN (Online): 2319-7064}

Index Copernicus Value (2013): 6.14 | Impact Factor (2014): 5.611

stagnating IMR and under-five mortality, the Integrated Management of Neonatal and Childhood Illnesses (IMNCI) program was implemented in India.

An estimated 10.6 million children under five years of age still die each year from preventable or treatable diseases. Many of these deaths are attributable to the conditions targeted by Integrated Management of Childhood Illness (IMCI). A large proportion of these deaths could be prevented through early, appropriate and low-cost treatment of sick children in the home or community.

The coverage of child-health interventions remains highly inadequate in India. The third National Family Health Survey (NFHS III) data showed that, in 2005-2006, only $43.5 \%$ of children were fully immunized; $26.2 \%$ of children, aged less than three years (under-3 children), suffering from diarrhoea, received oral rehydration salt (ORS) solution; and $64.2 \%$ of children with acute respiratory infection (ARI) or fever in the last two weeks were taken to a health facility. Only $23 \%$ of under-three children received breastfeeding within one hour of birth, and $46.3 \%$ aged $0-5$ months were exclusively breastfed ${ }^{5}$

Assessment is critical to know the degree of implementation of any program which aims to protect, promote and support the health of the weaker section of the society i.e. mothers and new born. In our country IMNCI is one such program which has been shown to be effective for Mothers and New born, and has been designed with the rural setting in mind. ${ }^{6}$

The IMNCI program aims to improve child survival rates by extending the interventions/services in homes, communities, and the health care system. IMNCI focuses specifically on the management of acute respiratory infections (ARI), diarrhea, measles, malaria and malnutrition, which are the main causes of childhood deaths in India.

In rural areas of developing countries, several reasons support the use of community health workers (CHWs) as a complement to health facilities as a source of medical care for children. Compared with health facilities, CHWs are geographically closer and available when health facilities are closed. Moreover, CHWs are community members, and therefore cultural and linguistic barriers that may be present at health facilities are overcome. ${ }^{9}$ Even though IMCI is being incorporated into the national health-care programmes of many developing countries, little is known about Health Workers performance. ${ }^{5}$

Female Health Workers are already working in the rural community as vital members of Indian public health care delivery system to prevent diseases, treat illnesses and promote health of the individual, family and community as a whole. The present study was carried out to assess the knowledge of ANMs (Female Health Workers) which will have an impact on performance of the health workers and coverage of services.

\subsection{Statement of the Problem}

A Study To Assess the Knowledge Regarding Integrated Management of Neonatal and Childhood Illnesses (IMNCI) Among ANMs In Selected Rural Sub centres.

\subsection{Objectives}

1) To assess the knowledge regarding Integrated Management Of Neonatal And Childhood Illnesses (IMNCI) Among ANMs

2) To find the association between the level of knowledge regarding IMNCI and the socio demographic variables of ANMs.

\section{Materials and Methods}

2.1 Research Design: This is a descriptive cross sectional study, conducted in rural areas of Nellore District, Andhra Pradesh. The study subjects were ANMs/(health workersfemale) working in rural sub centers.

2.2 Setting of the Study: Rural PHCs \& SCs of the Nellore District ,Andhra Pradesh. 224 AMNs(Multi Purpose HW-F) working in the 37 PHCs and the SCs under these PHCs in Nellore District were included for the study.

2.3 Sampling Technique: ANMS from 37 PHCs were selected by random sampling technique. All the health workers who participated in the study gave their consent to be part of the study $\&$ the response rate was $100 \%$.

All the available documents including Indian Public Health Standards (IPHS) $3 \&$ HWs training modules describing the expected performance of basic healthcare workers in India were reviewed. A pre tested structured in-depth instrument for data collection was developed in context to IMNCI.

2.4 Tools and Techniques: Data were obtained by using A) Self administered structured Questionnaire method was used to assess the knowledge regarding antenatal services.

2.5. Ethical Clearance Certificate: Ethical clearance certificate was obtained from author's affiliated Institutional ethics Committee.

2.6. DMHO: A formal written permission was obtained from the District Medical and Health Officer, Nellore District, A.P and a copy of the permission from DM\&HO letter was sent to all the selected PHCs for the study.

\section{Results}


International Journal of Science and Research (IJSR)

ISSN (Online): 2319-7064

Index Copernicus Value (2013): 6.14 | Impact Factor (2014): 5.611

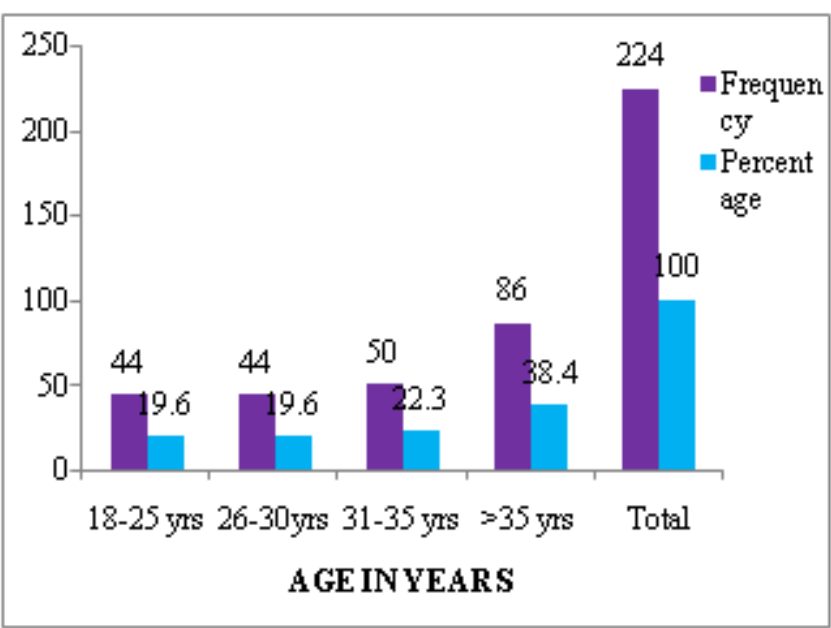

Figure 1: Frequency and Percentage Distribution of Based on Age of the ANMs

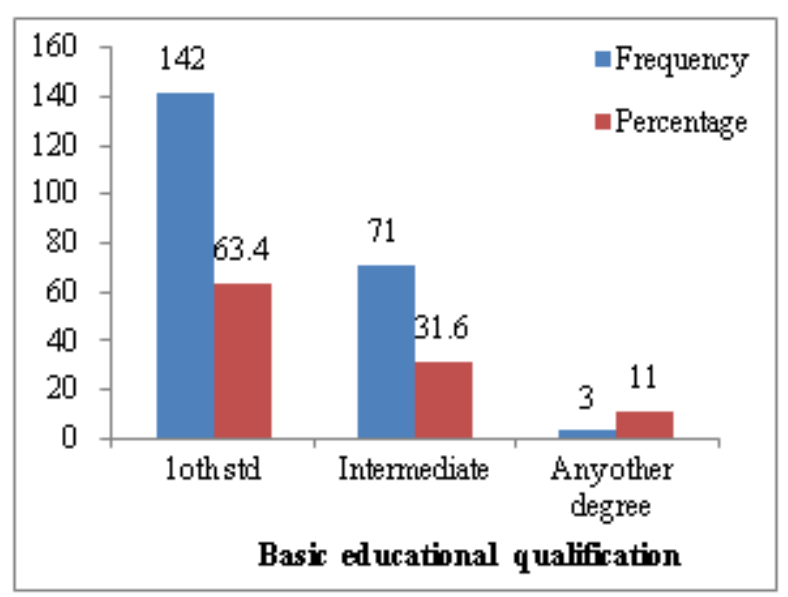

Figure 2: Frequency and percentage distribution of based on education of the ANMs.

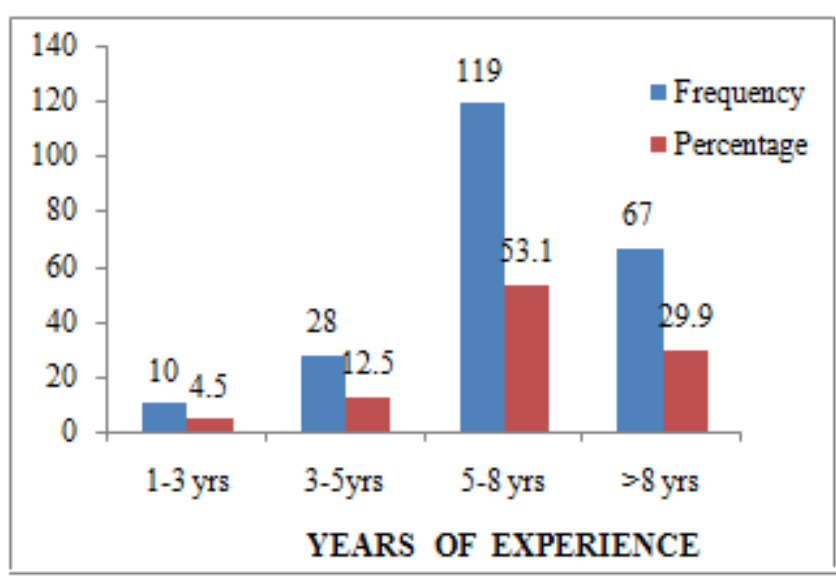

Figure 3: Frequency and percentage distribution based on experience

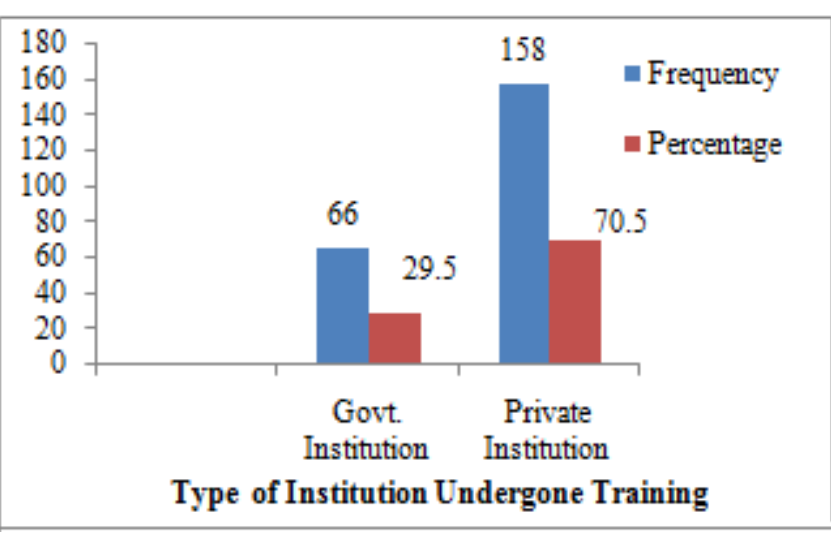

Figure 4: Frequency And Percentage Distribution Based On Type Of Institution Underwent Training

Table 2: Frequency And Percentage Distribution based on Knowledge Regarding IMNCI among ANMs. (N=224)

\begin{tabular}{|l|l|}
\hline S.No & Classification And Management Of Sick Child According \\
\hline
\end{tabular}

\begin{tabular}{|c|l|c|c|}
\hline 1. & \multicolumn{3}{|c|}{ to IMNCI } \\
\hline 2. & $\begin{array}{l}\text { Knowledge regarding the signs possible serious } \\
\text { bacterial infection }\end{array}$ & 88 & 39.3 \\
\hline 3. & Knowledge regarding Signs of local infection & 42 & 18.8 \\
\hline 4. & $\begin{array}{l}\text { Knowledge regarding signs of severe jaundice } \\
\text { dehydration in young infant }\end{array}$ & 81 & 36.2 \\
\hline 5. & $\begin{array}{l}\text { Knowledge regarding the Management of a } \\
\text { Young infant with severe dehydration }\end{array}$ & 61 & 27.2 \\
\hline 6. & $\begin{array}{l}\text { Knowledge of Signs and symptoms of chronic } \\
\text { diarrhea }\end{array}$ & 187 & 24.1 \\
\hline 7. & $\begin{array}{l}\text { Knowledge of Signs indicating severe } \\
\text { malnutrition in young infant }\end{array}$ & 51 & 22.8 \\
\hline 8. & $\begin{array}{l}\text { Knowledge about Classification of ear infection } \\
\text { in children }\end{array}$ & 152 & 67.9 \\
\hline 9. & $\begin{array}{l}\text { Knowledge about Classification of children } \\
\text { with convulsions during the present illness }\end{array}$ & 146 & 65.2 \\
\hline 10. & $\begin{array}{l}\text { Knowledge about The indicator of pneumonia } \\
\text { and assessment of ARI }\end{array}$ & 166 & 74.1 \\
\hline 11. & Knowledge on Management of pneumonia /ARI & 171 & 76.3 \\
\hline 12. & $\begin{array}{l}\text { Knowledge regarding The amount of fluid loss } \\
\text { seen in children with severe dehydration }\end{array}$ & 81 & 36.2 \\
\hline 13. & $\begin{array}{l}\text { Knowledge of Management of Children with } \\
\text { persistent diarrhea }\end{array}$ & 67 & 29.9 \\
\hline 14. & Knowledge of Signs of severe febrile disease & 120 & 53.6 \\
\hline 15. & $\begin{array}{l}\text { Knowledge about The signs of severe } \\
\text { complicated measles }\end{array}$ & 31 & 13.8 \\
\hline 16. & $\begin{array}{l}\text { Knowledge on Signs that indicate severe } \\
\text { malnutrition }\end{array}$ & 94 & 42 \\
\hline 17. & Knowledge on Assessment of anemia & 175 & 78 \\
\hline
\end{tabular}

Table 3: Frequency And Percentage Distribution based on level of knowledge $(\mathrm{N}=224)$

\begin{tabular}{|c|c|c|c|c|}
\hline $\begin{array}{c}\text { Level of knowledge } \\
\text { regarding } \\
\text { IMNCI }\end{array}$ & $\begin{array}{c}\text { Frequency } \\
\text { (f) }\end{array}$ & $\begin{array}{c}\text { Percentage } \\
(\%)\end{array}$ & Mean & SD \\
\hline Inadequate & 177 & 79.01 & & \\
Moderately adequate & 27 & 12.1 & 10.54 & 5.008 \\
Adequate & 20 & 8.2 & & \\
\hline
\end{tabular}

Tab.no.3. Shows the distribution of over all level of knowledge and the mean and SD of knowledge scores of the ANMs.Among 224 ANMs, 177(79.01) had inadequate knowledge,27(12.1) had adequate knowledge and only 20(8.2) of them had adequate knowledge regarding the 


\section{International Journal of Science and Research (IJSR) \\ ISSN (Online): 2319-7064}

Index Copernicus Value (2013): 6.14 | Impact Factor (2014): 5.611

IMNCI .The mean knowledge score is 10.54 and the SD is 5.008

Table 4: Association between the level of knowledge regarding IMNCI and demographic variables of ANMs

\begin{tabular}{|c|c|c|c|c|c|c|c|}
\hline \multirow{2}{*}{$\begin{array}{c}\text { Demographic } \\
\text { data }\end{array}$} & \multicolumn{2}{|c|}{ Inadequate } & \multicolumn{2}{|c|}{$\begin{array}{c}\text { Moderately } \\
\text { Adequate }\end{array}$} & \multicolumn{2}{|c|}{ Adequate } & \multirow[b]{2}{*}{$\mathrm{CHI}$} \\
\hline & f & $\%$ & f & $\%$ & $\mathbf{F}$ & $\%$ & \\
\hline \multicolumn{7}{|c|}{ Place of residence } & \\
\hline a. Rural & 55 & 24.6 & 4 & 1.8 & 4 & 1.8 & \multirow{4}{*}{$\begin{array}{c}d f=6 \\
S\end{array}$} \\
\hline b. Urban & 120 & 53.6 & 21 & 9.4 & 16 & 7.1 & \\
\hline c. Suburban & 0 & 0 & 2 & 0.9 & 0 & 0 & \\
\hline d. Slum & 2 & 0.9 & 0 & 0 & 0 & 0 & \\
\hline \multicolumn{7}{|c|}{ Type of institution } & \multirow{3}{*}{$\begin{array}{c}\mathbf{d f}=6 \\
\mathrm{~S}\end{array}$} \\
\hline A.govt & 47 & 20.9 & 13 & 5.8 & 6 & 2.7 & \\
\hline B.private & 130 & 58 & 14 & 6.3 & 14 & 6.3 & \\
\hline \multicolumn{7}{|c|}{ Training attended } & \multirow{3}{*}{$\begin{array}{c}d f=2 \\
S\end{array}$} \\
\hline A.yes & 155 & 69.2 & 16 & 7.1 & 18 & 8.1 & \\
\hline B.no & 22 & 9.8 & 11 & 4.9 & 2 & 0.9 & \\
\hline
\end{tabular}

Tab.no 4. shows the association between the level of knowledge on IMNCI and socio demographic variables. There is a significant association between the level of knowledge and place of residence and type of institution studied, and refresher course attended at $\mathrm{p}=0.05$ level.

\section{Discussion}

\section{Description of back ground variables:}

With regard to age, 44(19.6\%) belong to $18-25 \mathrm{yrs}$, $44(19.6 \%)$ belong to26-30yrs, $50(22.3 \%)$ belong to $31-35 y r s$ and, $86(38.4 \%)$ belong to above 35yrs. With regard to education, 142(19.6\%) studied $10^{\text {th }} \mathrm{std}, 71(31.6 \%)$ studied intermediate, and $3(11 \%)$ studied degree. With regard to experience , 10(4.5\%)have 1-3 yrs of experience, $28(19.6 \%)$ have 3-5yrs,119(53.3\%) have 5-8 yrs and 67 (29.9\%) have $>8$ yrs of experience. With regard to marital status, $187(83.5 \%)$ are married,32 $(14.3 \%)$ are unmarried and $5(2.2 \%)$ are separated/widow. With regard to type of institution underwent ANM course, 66(29.5\%) studied in Govt Institution and $158(70.5 \%)$ studied in private Institutions.

\section{Level of knowledge regarding IMNCI among ANMs:}

Tabno.2 shows the distribution of knowledge regarding IMNCI $88(39.01 \%)$ had knowledge regarding the signs of possible serious bacterial infection, 42(18.2\%) had knowledge regarding Signs of local infection, 81(36.2\%) had knowledge regarding The signs of severe jaundice, $61(27.2 \%)$ had the knowledge about the signs of severe dehydration in young infant , 187(83.5\%) had knowledge , $166(74.1 \%)$ had knowledge regarding the indicator of pneumonia, Regarding signs of chronic diarrhea 187(76.3 $\%$ ) had knowledge ,regarding management of pneumonia171(76.3) had knowledge, 120 (53.6\%) had knowledge regarding severe febrile disease, 94 (42\%)had knowledge about signs of severe malnutrition, $180(80.4 \%)$ had knowledge about danger signals of diarrhea, 126 (56\% )had knowledge regarding the management of oral thrush and $174(7.7 \%)$ had knowledge about the contraindications for DPT immunization.
Tab.no.3. Shows the distribution of over all level of knowledge and the mean and SD of knowledge scores of the ANMs. Among 224 ANMs, 177(79.01) had inadequate knowledge,27(12.1) had adequate knowledge and only 20(8.2) of them had adequate knowledge regarding the IMNCI .The mean knowledge score is 10.54 and the SD is 5.008

The findings of this study are consistent with a study conducted by C. Roy et all To assess the Job Performance of A.N.Ms and AWWs and to find out the Gap in their knowledge and skill of the IMNCI trained A.N.Ms and AWWs. A stratified sampling method was applied to select 35 IMNCI trained AWWs and 25 IMNCI trained A.N.Ms. They were visited at their workplace and observations were made on children they treated/tended to. A predesigned questionnaire was used to assess their observations. The results of the study showed that Local Bacterial Infection $(16 \%)$ was the most common cause for which mothers came to the A.N.Ms/AWWs in the age group 0-2 months. Cough and cold $(42.85 \%)$ was the most common cause for which mothers came to the A.N.Ms/AWWs in the age group > 2 months -5 years of age. Only $35 \%$ of the AWWs and $50 \%$ of the A.N.Ms were making 0 day visit in their Locality. $65 \%$ ANMs and 70\% AWWs did not knew to check growth chart. This study concludes that A.N.Ms and AWWs need more supervision and incentive based training for better results.

\section{Association between the level of knowledge regarding IMNCI and the socio demographic variables of ANMs}

Tab.no 4. shows the association between the level of knowledge on IMNCI and socio demographic variables. There is a significant association between the level of knowledge and Place of residence and type of institution studied, and refresher course attended at $p=0.05$ level

\section{Recommendations for Further Research}

1) A similar study can be replicated with the different populations like Anganwadi workers, and Registered Nurses.

2) A study can be undertaken on assessment of FHWs' competencies regarding IMNCI.

3) A similar study can be conducted with the follow-up at six months and one year after implementing intervention with skill training programmes.

4) A study can be conducted to assess the effectiveness of different types of refresher and skill training programmes on knowledge, skills and practice among community health workers in rural and urban PHCs.

\section{Conclusion}

The study concludes that majority of the ANMs have lack of knowledge on many components of IMNCI. The study indicates the need for supervision and training for better results and quality of services. 


\section{International Journal of Science and Research (IJSR) \\ ISSN (Online): 2319-7064}

Index Copernicus Value (2013): 6.14 | Impact Factor (2014): 5.611

\section{References}

[1] Sundararaju A, Subramanian S. Children of Today Are Citizens of Tomorrow. Social welfare. 2005; 52 (2): 3234

[2] Pasayat Chitrasen. Child Labour and Child Rights. Social Welfare. 2004; 51 (2): 4-9.

[3] Bahuguna Nitin Jugran. Toxic War on Children. Social Welfare. 2004; 51 (2):10-11.

[4] Jones Gareth, Schultink Werner, Babille Marzio. Child Survival in India. Indian Journal of Pediatrics. 2006; 73 (6): 479-487.

[5] NFHS 3 Data release.

[6] Rana R. et al., Int J Dent Health Sci 2015; 2(1):66-75.

[7] Centers for Disease Control and Prevention (CDC). Health Worker Performance after Training in Integrated Management of Childhood Illness-Western Province, Kenya, 1996-1997. MMWR Morb Mortal Wkly Rep. 1998; 47 (46): 998-1001.

[8] World Health Organization \& Unicef. Management of Sick Children by Community Health Workers Intervention Models and Programme Examples. 2006.

[9] Madhavi Mankar et al Role of community health worker in the treatment of minor ailments among children, Indian J. Prev. Soc. Med Vol. 43 No.3 JulySeptember, 2012.

[10] Kumar R. Integrated Management of Childhood Illness Strategy: Opportunity and Challenges. Ind J. Pub. Hlth. March 2003; 48 (1): 3-6. 